\title{
Corrigendum to "Socioeconomic Determinants of Mangrove Exploitation and Seagrass Degradation in Zanzibar: Implications for Sustainable Development"
}

\author{
Amina A. Nchimbi $\mathbb{D}^{1,2}$ Mwanahija S. Shalli, ${ }^{2}$ Narriman S. Jiddawi, ${ }^{3}$ \\ and Mwita M. Mangora ${ }^{2}$ \\ ${ }^{1}$ School of Biological Sciences, University of Dodoma, P.O. Box 338, Dodoma, Tanzania \\ ${ }^{2}$ Institute of Marine Sciences, University of Dar es Salaam, P.O. Box 668, Zanzibar, Tanzania \\ ${ }^{3}$ Institute of Fisheries Research Zanzibar, P.O. Box 159, Zanzibar, Tanzania \\ Correspondence should be addressed to Amina A. Nchimbi; asiyaanchimbi@gmail.com
}

Received 28 August 2020; Accepted 28 August 2020; Published 12 September 2020

Copyright (c) 2020 Amina A. Nchimbi et al. This is an open access article distributed under the Creative Commons Attribution License, which permits unrestricted use, distribution, and reproduction in any medium, provided the original work is properly cited.

In the article titled "Socioeconomic Determinants of Mangrove Exploitation and Seagrass Degradation in Zanzibar: Implications for Sustainable Development" [1], concerns with the authorship list were raised in May 2019.

Following an investigation into the authorship of the article, the contributors to the study have agreed that the correct list should be as above. The acknowledgements section is also being updated as follows to acknowledge Liberatus D. Lyimo for his contribution to the study and to amend the funding statement:

\section{Acknowledgments}

The authors thank the Sida program of the Institute of Marine Sciences (IMS), University of Dar-es-Salaam, for providing financial support and extend sincere acknowledgment to the Coastal Ecosystem Services in East Africa (CESEA) for supporting this project. We thank the Mangrove Committee Members and local authorities in the study sites for allowing this work to be conducted in their areas. The authors apologise for the errors in the original article.

\section{References}

[1] A. A. Nchimbi and L. D. Lyimo, "Socioeconomic determinants of mangrove exploitation and seagrass degradation in Zanzibar: implications for sustainable development," Journal of Marine Biology, vol. 2019, Article ID 7684924, 11 pages, 2019. 